\title{
Infertility in the light of new scientific reports - focus on male factor
}

\author{
Piotr Szkodziak', Slawomir Wozniak', Piotr Czuczwar' ${ }^{1}$, Ewa Wozniakowska', Pawel Milart ${ }^{1}$, \\ Artur Mroczkowski², Tomasz Paszkowski ${ }^{1}$ \\ $13^{\text {rd }}$ Chair and Department of Gynecology Medical University, Lublin, Poland \\ 2 "Ovum" Reproduction and Andrology, Infertility Centre, Lublin, Poland
}

Szkodziak P, Wozniak S, Czuczwar P, Wozniakowska E, Milart P, Mroczkowski A, Paszkowski T. Infertility in the light of new scientific reports - focus on male factor. Ann Agric Environ Med. 2016; 23(2): 227-230. doi: 10.5604/12321966.1203881

\begin{abstract}
Epidemiological data indicate that infertility is a problem of global proportions, affecting one- fifth of couples trying to conceive worldwide (60-80 mln). According to the trends observed, the problem is predicted to increase by another two million cases annually. In Poland, infertility-related issues are found in about $19 \%$ of couples, including $4 \%$ with infertility and $15 \%$ with limited fertility. Inability to conceive occurs equally in men and women (50\%), irrespective of the direct cause. Although it is generally thought that reproductive issues concern women, infertility affects men and women equally. This study is an attempted to systematize knowledge about the role of the male factor in infertility, particularly current knowledge concerning the environmental factors of infertility. For this purpose, the Medline and CINAHL databases and the Cochrane Library was searched for articles published in English during the last 10 years, using the following keywords: infertility, male factor, semen examination and environmental factor of infertility.
\end{abstract}

\section{Key words}

Infertility, enviromental factors, sperm quality, treatment strategies

\section{INTRODUCTION}

The first guidelines regarding examinations of semen quality were elaborated and published by the World Health Organization (WHO) in 1980. Since that time, they have been updated four times, with the latest and currently valid guidelines were published in 2010, which introduce numerous significant changes compared to the earlier WHO recommendations [1]. Epidemiological data indicate that infertility is a problem of global proportions affecting onefifth of couples trying to conceive worldwide. According to the trends observed, the problem is predicted to increase by another two million cases annually $[2,3]$. In Poland, infertility-related issues are diagnosed in about $19 \%$ of couples, including $4 \%$ with infertility and $15 \%$ with limited fertility [4]. The inability to conceive occurs equally in men and women (50\%), irrespective of the direct cause. Although it is generally thought that reproductive issues concern women, infertility affects men and women equally [3].

\section{OBJECTIVE}

The presented study aimed at systematizing knowledge of the male factor of infertility, particularly current knowledge of the environmental factors of infertility. The Medline, CINAHL databases and the Cochrane Library were searched for articles published in English during the recent 10 years, using the following key words: infertility, male factor, semen examination and environmental factor of infertility.

The reference values suggested by the WHO in 2010 for individual parameters of semen, such as ejaculate volume and $\mathrm{pH}$, sperm concentration, sperm count, viability, motility and

Address for correspondence: Piotr Szkodziak, $3^{\text {rd }}$ Chair and Department of Gynecology Medical University, Lublin, Poland

E-mail: piotr.szkodziak@gmail.com

Received: 21 May 2014; accepted: 12 July 2014 morphology, were based on studies involving 4,500 men; the time to achieve pregnancy was also monitored. In the above studies, the reference group included men whose partners became pregnant during the period of 12 months or shorter. Based on the selected reference group, normal values of sperm parameters were determined $[1,5]$.

There is a widespread opinion that body weight affects male fertility; however, scientific evidence confirming the above thesis is not convincing and there are no randomized studies investigating this issue. A study by Wise did not confirm any relationship between obesity in men and reduced fertility [6]. However, the most recent reports indicate a higher risk of sperm DNA damage in obese men and negative effects of obesity on semen parameters [7]. Moreover, possible effects of weight loss on improved male fertility have been considered [7].

In women, the incidence of infertility increases with age [8]. Otherwise, there is no evidence that the age of men above 35 years significantly affects their fertility. According to Dunson, the percentage of couples observed for 12 cycles who did not spontaneously conceive was $18 \%$ when the male partner was 35 years old and $28 \%$ when 40 years old [9].

The causal relationship between tobacco smoking and male fertility was not explicitly confirmed. However, there are some studies indicating that such a relationship exists. Smokers are characterised by decreased sperm count, on average by $23 \%$, reduced mobility (by $13 \%$ ) and increased sperm DNA fragmentation, compared to non-smokers [10]. It is recommended to stop or cut down on tobacco smoking $[11,12]$.

Increased consumption of caffeine by women $(>500 \mathrm{mg}$ daily) is associated with reduced fertility. There are numerous studies indicating that caffeine is a potential cause of infertility in women, including those undergoing in vitro fertilization (IVF) [11-13]. The study by Klonoff-Cohen demonstrated that caffeine consumption by men did not affect the sperm quality, or course of IVF and health of newborns [14]. This thesis was confirmed in later studies $[11,15]$. 
Information regarding the effects of alcohol on fertility is divergent. On the one hand, there are data showing that intensive alcohol drinking can affect the fertility of men and women [16]. In men, consumption of alcohol can lead to atrophy of the testes, impotence, reduced libido and worse quality of sperm [16]. To date, one study has been found which analysed alcohol drinking by men and women as a primary risk factor of failures in assisted reproductive technology (ART) [17]. Based on the above data, the American Society for Reproductive Medicine (ASRM) recommends that couples should avoid excessive alcohol drinking ( $\geq 2$ drinks a day) during attempts to conceive, although there are no conclusive data evidencing that alcohol drinking adversely affects fertility [12].

Marihuana is the most commonly used recreational drug worldwide [18]. It contains various active ingredients, in particular cannabinoids, which act on the central and peripheral nervous system and impair the reproductive function at many levels. Cannabinoid receptors are located in many organs, including the reproductive system, e.g. the ovary, uterus, spermatic ducts and testes. In women, excessive use of marihuana decreases the level of luteinizing hormone (LH) [19]. In men, cannabinoids adversely affect spermatogenesis by modulating apoptosis of Sertoli cells and by reducing the production of testosterone by Leydig cells, which decreases the motility of sperm, inhibits its maturation and induces poor acrosome reaction $[18,19]$.

Anabolic steroids are commonly abused. Their use has increased during the last four years, particularly in the male population to increase muscle strength and performance. Long-term use of these substances negatively affects male fertility. They inhibit the hypothalamic-pituitary-testicular axis, which results in reduced production of endogenous testosterone. This leads to erectile disorders and causes oligoand asthenozoospermia. The effects of anabolic steroids are reversible once their use is discontinued; however, it may take even a year to restore normal potency and sperm parameters [20].

Stress-related sexual disorders undoubtedly affect reproductive failures. This issue is extremely complex. Stress affects the responses of the immune and hormonal system. The current study prove that stress can suppress reproductive functions, delaying menarche and inducing amenorrhoea, disorders of the hypothalamic-pituitary-ovarian axis and early menopause [21, 22]. Moreover, a positive correlation between adverse preconception events and conception failures was demonstrated [23]. Mental stress in men affects the quality of semen. Severe depression is associated with decreased levels of testosterone, thus affecting the quality of spermatogenesis $[22,24]$. Psychological counselling is likely to reduce the level of stress of infertile couples, which can facilitate coping with this problem, improve the quality of life, enhance motivation for treatment and promote lifestyle changes (elimination of the factors mentioned above) [25]. However, it is not clear whether such interventions can improve the percentage of pregnancies. The study by Ramezanzadeh confirm the effects of reduced stress on procreation results, whereas a study by Hashemi did not confirm such effects $[26,27]$. Hashemi, however, argues that psychological counselling is necessary to decrease anxiety in infertile couples to improve their quality of life.

Spermatogenesis occurs mostly at $37^{\circ} \mathrm{C}$; therefore, overwarming of the testes has been implicated among numerous causes of infertility. Testicular over-warming leads to oligozoospermia. This process is reversible and men trying to conceive a child should consciously avoid this factor $[7,11]$.

When infertile couples start to seek professional help, male factor infertility is diagnosed in $25-50 \%$ of cases [ 2 , 3 ]; therefore, therapeutic decisions are made equally often due to female and male causes of infertility. In order to better understand the choice of a given male infertility treatment option, all causes of male infertility are divided into four groups:

1) idiopathic;

2) obstructive (extra-testicular)

3) primary (testicular);

4) secondary (pre-testicular) [2, 3, 28].

According to various studies, idiopathic infertility occurs in from $10 \%$ even up to $50 \%$ of cases $[2,3,28]$. The cause of inability to conceive cannot be univocally determined and oligo- or/and astheno- or/and teratozoospermia are observed in men at normal concentrations of testosterone (T) and gonadotropins (FSH, LH); physical examinations do not reveal any pathology within the gonads. This type of infertility is likely to be related to emotional disturbances, which can be accompanied by depression, various sexual disorders and lack of sexual satisfaction [21,22]. The available literature findings indicate that microelement deficiencies are essential in this type of infertility [29-33].

Extra-testicular infertility is associated with impaired transport of sperm, inability to perform sexual intercourse, or ejaculation disturbances. The adverse effects of some drugs are implicated in this type of infertility. Extra-testicular infertility can result from post-operative complications and venereal diseases. Moreover, some systemic diseases, e.g. cystic fibrosis, cause this type of infertility associated with the obstruction and aplasia of spermatic ducts, defined as congenital bilateral aplasia of the vas deferens $[2,3,28]$.

Testicular infertility is a disorder at the level of Sertoli or/ and Leydig cells and is the major cause of male infertility. It can result from both congenital defects (chromosomal aberrations - Klinefelter syndrome) and acquired diseases and problems, e.g. varicoceles, spinal injuries, testicular cancer, inflammations, chemotherapy, radiation therapy, use of alcohol, cocaine, and some drugs (nitrofurantoin, sulfasalazine, colchicine) $[34,35]$.

Pre-testicular infertility is caused by disorders of the hypothalamic-pituitary axis. It is most commonly induced by tumours, inflammations, trauma and vascular changes in the central nervous system. Moreover, pre-testicular infertility can be a symptom of endocrine, systemic or genetically conditioned diseases (Kallmann syndrome). Proper functioning of the hypothalamic-pituitary-testicular axis can also be impaired by some drugs, such as androgens (testosterone, anabolic steroids), high doses of corticosteroids, cyproterone or spironolactone. Pre-testicular infertility induces hypogonadotropic hypogonadism $(\mathrm{HH})$, which affects $2 \%$ of infertile men. HH involves impaired secretion of folliculotropic hormone (FSH) and luteinizing hormone (LH), leading to the lack or insufficient stimulation of testes by both gonadotropins $[36,37]$.

The therapeutic strategy in male infertility is dictated by time, costs and aetiology of male infertility. Assisted reproductive technology (ART) is relatively expensive and emotionally exhausting, yet can undoubtedly accelerate conception in the majority of male infertility types. In 
patients with limited fertility due to sexual disturbances, thus insufficient numbers of vaginal intercourses, the treatment of urogenital diseases which cause those disorders is usually effective. Men with retrograde ejaculation (to the urinary bladder) or lack of ejaculation (extra-testicular cause) should have their sperm collected from the urine or testes. In most cases, sperm from testes/epididymis are collected surgically (testicular sperm extraction/micro-testicular sperm extraction TESE/M-TESE); percutaneous epididymal sperm aspiration (PESA) can also be applied. The sperm collected in such a way are best for IVF, using intracytoplasmic sperm injection (ICSI) [38]. There are reports of successful attempts of conception with the sperm extracted from urine in patients with retrograde ejaculation after intra-uterine insemination (IUI) [39]. Retrograde ejaculation in cases caused by neuropathic changes can be treated conservatively (a-sympathicomimetics, e.g. ephedrine) or by physical stimulation (electro-ejaculation) [40].

In cases of primary infertility due to testis defects, assisted reproductive techniques are the best and the only chance to conceive; the best therapeutic alternative for pretesticular infertility (hypogonadotropic hypogonadism) is the therapy with exogenous gonadotropins ( $\mathrm{FSH} / \mathrm{LH}$ ) or drugs stimulating the secretion of endogenous gonadotropins $[28,35,41]$.

The widespread treatment of pre-testicular infertility involves substitutive therapy with gonadotropins, use of aromatase inhibitors and selective estrogen receptor modulators (SERMs) [28, 41].

The best treatment effects in cases of infertility accompanied by hypogonadotropic hypogonadism are achieved with gonadotropin substitutive therapy. According to the literature data, optimal outcomes are observed when the treatment is continued for 9-10 weeks to complete all the stage of spermatogenesis. Substitutive therapy with gonadotropins can be applied to improve spermatogenesis in patients with low serum levels of gonadotropins and testosterone, as well as those with oligozoospermia [38].

In patients with deficiency of gonadoliberins (gonadotropinreleasing hormone $\mathrm{GnRH}$ ), as observed in the Kallmann syndrome, substitutive therapy with pulsatile administration of $\mathrm{GnRH}$ analogues can be used. The treatment is not widely available as it requires the use of a special personal pump administering the drug subcutaneously; moreover, this option is not effective in men with pituitary diseases. Exogenous administration of LH and FSH is most commonly used for substitutive therapy with gonadotropins. Androgens should be administered during the therapy. The treatment with LH should be preceded by administration of human chorionic gonadotropin (hCG), in a dose of 1,000-2,000 IU, subcutaneously, 2-3 times a week; lower doses of hCG (500-750 IU) are also effective [42]. Since in some men (particularly those with the pre-treatment volume of testes $\geq 8 \mathrm{~cm} 3$ ), spermatogenesis and fertility improve after administration of hCG alone, and considering the high costs of FSH, hCG is often administered in monotherapy for six months, testing the semen once a month. Men with deficiency of gonadotropins developing after pubescence can respond well to hCG monotherapy, whereas those with deficient gonadotropins before pubescence should always be provided with the therapy combining hCG and FSH [43].

In men with idiopathic infertility, when oligozoospermia or azoospermia is observed, the treatment of choice is assisted reproductive technology (ART). The use of ART (including ICSI) leads to pregnancy in $40-45 \%$ of cases [44]. ICSI can be performed from ejaculate spermatozoa or sperm collected by TESE or M-TESE. In $60 \%$ of cases of infertile men with azoospermia, a small amount of sperm can be obtained using the above-mentioned techniques and ICSI can be performed [44]. It should be remembered, however, that the use of ART is associated with the risk of multiple pregnancies; moreover, the percentages of chromosome aberrations in such embryos are higher.

The role of micro-element deficiencies in the pathogenesis of male infertility has been increasingly stressed, which particularly concerns idiopathic infertility and some forms of extra-testicular infertility. It has been demonstrated that dietary supplementation of microelements, such as L-carnitine, L-arginine, vitamin E, folic acid, zinc, selenium, glutathione or co-enzyme Q, can markedly improve sperm parameters, thus improving obstetric outcomes in these men [29-31]. The substances listed above have antioxidative properties, which proves that oxidative stress, i.e. imbalance between the action of reactive oxygen species in the body and the biological capacity of quick detoxication of reactive products of oxidation, can cause injuries to the majority of cell structures. Most high metabolism cells (including sperm) preserve the reductive environment by the activity of enzymes maintaining the state of reduction. Disturbances in the normal state of reduction can induce toxic effects through production of peroxides and free radicals causing oxidative damage to cell components, particularly to proteins, lipids and their genetic material $[33,45]$. In male gametes, this not only decreases their number and motility but also adversely affects their structure and ability to fertilise the egg cell $[33,45]$.

Although the aetiology of oligoasthenoteratozoospermia is poorly known, idiopathic reduction in fertility can be considered a disorder to which many factors contribute, including the genetic, environmental and lifestyle-related. Nutrition is essential for therapy. The majority of basic compounds required for DNA synthesis and spermatogenesis comes from dietary products; therefore, the concentration of nutrients can have a significant impact on the quality of sperm and ability to conceive [46]. Importantly, male infertility resulting from dietary deficiencies responds well to treatment and preventive supplementation. The multifaceted therapeutic approach to fertility improvement should recommend correction of dietary disproportions in order to support optimal production and quality of sperm [47]. There are studies demonstrating that the use of suitably prepared diet supplements containing the above-mentioned microelements for at least three months, substantially improved the quality of sperm (increased concentration and motility, improved morphological structure of sperm) [29].

Most cases of extra-testicular (obstructive) male infertility require surgical interventions. Varicoceles management involves surgical treatment, including laparoscopic procedures, embolisation and laser obliteration [48, 49]. Available data demonstrate that the treatment of varicoceles results in satisfactory outcomes: improved quality of sperm is observed in $70-80 \%$ of men; however, there is a lack of improvement in 15-20\% while deterioration occurs in about $5 \%$. The procedures improve the quality of sperm. Moreover, in young men operative treatment prevents damage of the testis and maintains its normal functioning [50]. 


\section{CONCLUSIONS}

The end-points in male infertility treatment are the percentages of pregnancies and live births. The treatment of male infertility is a complex and time-consuming problem, and the outcomes of therapy are often unsatisfactory. The treatment plan has to be tailored individually for each infertile couple. Moreover, it should be remembered that successful treatment of male infertility should result not merely in improved sperm parameters, but conceiving and delivering a healthy newborn.

\section{REFERENCES}

1. World Health Organization D of RH and R. WHO laboratory manual for the examination and processing of human semen. Fifth edition. Geneva; 2010 .

2. Cocuzza M, Alvarenga C, Pagani R. The epidemiology and etiology of azoospermia. Clinics (Sao Paulo). 2013;68 Suppl 1:15-26.

3. Winters BR, Walsh TJ. The epidemiology of male infertility. Urol Clin North Am. 2014; 41(1): 195-204.

4. Bablok L, Dziadecki W, Szymusik I, Wolczynski S, Kurzawa R, Pawelczyk L, Jedrzejczak P, Hanke W, Kaminski P, Wielgos M. Patterns of infertility in Poland - multicenter study. Neuro Endocrinol Lett. 2011; 32(6): 799-804.

5. Ford WCL. Comments on the release of the 5th edition of the WHO Laboratory Manual for the Examination and Processing of Human Semen. Asian J Androl. 2010; 12(1): 59-63.

6. Wise LA, Rothman KJ, Mikkelsen EM, Sørensen HT, Riis A, Hatch EE. An internet-based prospective study of body size and time-topregnancy. Hum Reprod. 2010; 25(1): 253-64.

7. Hajshafiha M, Ghareaghaji R, Salemi S, Sadegh-Asadi N, SadeghiBazargani $\mathrm{H}$. Association of body mass index with some fertility markers among male partners of infertile couples. Int J Gen Med. 2013; 6: 447-51.

8. Weeg N, Shalom-Paz E, Wiser A. Age and infertility: the clinical point of view. Minerva Ginecol. 2012; 64(6): 477-83.

9. Dunson DB, Baird DD, Colombo B. Increased infertility with age in men and women. Obstet Gynecol. 2004; 103(1): 51-6.

10. Taha EA, Ezz-Aldin AM, Sayed SK, Ghandour NM, Mostafa T. Smoking influence on sperm vitality, DNA fragmentation, reactive oxygen species and zinc in oligoasthenoteratozoospermic men with varicocele. Andrologia. 2013.

11. Anderson K, Nisenblat V, Norman R. Lifestyle factors in people seeking infertility treatment - A review. Aust N Z J Obstet Gynaecol. 2010; 50(1): 8-20.

12. Optimizing natural fertility: a committee opinion. Fertil Steril. 2013; 100(3): 631-7.

13. Chavarro JE, Rich-Edwards JW, Rosner BA, Willett WC. Caffeinated and alcoholic beverage intake in relation to ovulatory disorder infertility. Epidemiology. 2009; 20(3): 374-81.

14. Klonoff-Cohen H. Female and male lifestyle habits and IVF: what is known and unknown. Hum Reprod Update. 2005; 11(2): 179-203.

15. Mmbaga N, Luk J. The impact of preconceptual diet on the outcome of reproductive treatments. Curr Opin Obstet Gynecol. 2012; 24(3): 127-31.

16. Condorelli RA, Calogero AE, Vicari E, La Vignera S. Chronic consumption of alcohol and sperm parameters: our experience and the main evidences. Andrologia. 2014.

17. Klonoff-Cohen H, Lam-Kruglick P, Gonzalez C. Effects of maternal and paternal alcohol consumption on the success rates of in vitro fertilization and gamete intrafallopian transfer. Fertil Steril. 2003; 79(2): 330-9.

18. Bari M, Battista N, Pirazzi V, Maccarrone M. The manifold actions of endocannabinoids on female and male reproductive events. Front Biosci (Landmark Ed). 2011; 16: 498-516.

19. Alvarez $S$, Fallet $C$. [Role of toxic factors in the fecundity of the couple]. J Gynecol Obstet Biol Reprod (Paris). 2010; 39(1 Suppl): 39-40.

20. De Souza GL, Hallak J. Anabolic steroids and male infertility: a comprehensive review. BJU Int. 2011; 108(11): 1860-5

21. Barazani Y, Katz BF, Nagler HM, Stember DS. Lifestyle, environment, and male reproductive health. Urol Clin North Am. 2014; 41(1): 55-66.

22. Bhongade MB, Prasad S, Jiloha RC, Ray PC, Mohapatra S, Koner BC. Effect of psychological stress on fertility hormones and seminal quality in male partners of infertile couples. Andrologia. 2014.
23. Coughlan C, Walters S, Ledger W, Li TC. A comparison of psychological stress among women with and without reproductive failure. Int J Gynaecol Obstet. 2014;124(2):143-7.

24. Jóźków P, Mędraś M. Psychological stress and the function of male gonads. Endokrynol Pol. 2012; 63(1): 44-9.

25. Hakim LZ, Newton CR, MacLean-Brine D, Feyles V. Evaluation of preparatory psychosocial counselling for medically assisted reproduction. Hum Reprod. 2012; 27(7): 2058-66.

26. Hashemi S, Simbar M, Ramezani-Tehrani F, Shams J, Majd HA. Anxiety and success of in vitro fertilization. Eur J Obstet Gynecol Reprod Biol. 2012; 164(1): 60-4.

27. Ramezanzadeh F, Noorbala A-A, Abedinia N, Rahimi Forooshani A, Naghizadeh MM. Psychiatric intervention improved pregnancy rates in infertile couples. Malays J Med Sci. 2011; 18(1): 16-24.

28. Bhasin S. Approach to the infertile man. J Clin Endocrinol Metab. 2007; 92(6): 1995-2004

29. Imhof M, Lackner J, Lipovac M, Chedraui P, Riedl C. Improvement of sperm quality after micronutrient supplementation. ESPEN J. 2012; 7(1): e50-e53.

30. Sigman M, Glass S, Campagnone J, Pryor JL. Carnitine for the treatment of idiopathic asthenospermia: a randomized, double-blind, placebocontrolled trial. Fertil Steril. 2006; 85(5): 1409-14.

31. Balercia G, Regoli F, Armeni T, Koverech A, Mantero F, Boscaro M. Placebo-controlled double-blind randomized trial on the use of L-carnitine, L-acetylcarnitine, or combined L-carnitine and L-acetylcarnitine in men with idiopathic asthenozoospermia. Fertil Steril. 2005; 84(3): 662-71.

32. Balercia G, Mosca F, Mantero F, Boscaro M, Mancini A, RicciardoLamonica G, Littarru G. Coenzyme Q(10) supplementation in infertile men with idiopathic asthenozoospermia: an open, uncontrolled pilot study. Fertil Steril. 2004; 81(1): 93-8.

33. Sheweita SA, Tilmisany AM, Al-Sawaf H. Mechanisms of male infertility: role of antioxidants. Curr Drug Metab. 2005; 6(5): 495-501.

34. Aksglaede L, Juul A. Testicular function and fertility in men with Klinefelter syndrome: a review. Eur J Endocrinol. 2013; 168(4): R67-76.

35. Tournaye H. Male factor infertility and ART. Asian J Androl. 2012; 14(1): 103-8.

36. King TFJ, Hayes FJ. Long-term outcome of idiopathic hypogonadotropic hypogonadism. Curr Opin Endocrinol Diabetes Obes. 2012; 19(3): 204-10.

37. Silveira LFG, Latronico AC. Approach to the patient with hypogonadotropic hypogonadism. J Clin Endocrinol Metab. 2013;9 8(5): 1781-8.

38. Anawalt BD. Approach to male infertility and induction of spermatogenesis. J Clin Endocrinol Metab. 2013; 98(9): 3532-42.

39. Szkodziak P, Plewka K, Woźniak S, Czuczwar P, Mroczkowski A. Modified semen processing technique in a retrograde ejaculation infertile patient for the purpose of intrauterine insemination - a case report. Hum Reprod. 2012; 27(suppl 2): 121-2.

40. Ohl DA, Quallich SA, Sønksen J, Brackett NL, Lynne CM. Anejaculation and retrograde ejaculation. Urol Clin North Am. 2008; 35(2): 21120,VIII.

41. Kim ED, Crosnoe L, Bar-Chama N, Khera M, Lipshultz LI. The treatment of hypogonadism in men of reproductive age. Fertil Steril. 2013; 99(3): 718-24.

42. Coviello AD, Matsumoto AM, Bremner WJ, Herbst KL, Amory JK, Anawalt BD, Sutton PR, Wright WW, Brown TR, Yan X, Zirkin $\mathrm{BR}$, Jarow JP. Low-dose human chorionic gonadotropin maintains intratesticular testosterone in normal men with testosterone-induced gonadotropin suppression. J Clin Endocrinol Metab. 2005; 90(5): 2595-602.

43. Han TS, Bouloux PMG. What is the optimal therapy for young males with hypogonadotropic hypogonadism? Clin Endocrinol (Oxf). 2010; 72(6): 731-7.

44. Palermo GD, Neri Q V, Takeuchi T, Rosenwaks Z. ICSI: where we have been and where we are going. Semin Reprod Med. 2009; 27(2): 191-201.

45. Harnisch B, Oates R. Genetic disorders related to male factor infertility and their adverse consequences. Semin Reprod Med. 2012;30(2): 105-15

46. Ebisch IMW, Thomas CMG, Peters WHM, Braat DDM, SteegersTheunissen RPM. The importance of folate, zinc and antioxidants in the pathogenesis and prevention of subfertility. Hum Reprod Update. 2007; 13(2): 163-74.

47. Afeiche MC, Bridges ND, Williams PL, Gaskins AJ, Tanrikut C, Petrozza JC, Hauser R, Chavarro JE. Dairy intake and semen quality among men attending a fertility clinic. Fertil Steril. 2014; 101(5): 1280-1287.e2.

48. Raheem OA. Surgical management of adolescent varicocele: Systematic review of the world literature. Urol Ann. 2013; 5(3): 133-9.

49. Serefoglu EC, Saitz TR, La Nasa JA, Hellstrom WJ. Adolescent varicocoele management controversies. Andrology. 2013; 1(1): 109-15.

50. Cayan S, Shavakhabov S, Kadioğlu A. Treatment of palpable varicocele in infertile men: a meta-analysis to define the best technique. J Androl. 2009; 30(1): 33-40. 